\title{
ELUSIVE REASONS AND THE MOTIVATIONAL CONSTRAINT
}

\author{
Benjamin Cohen Rossi
}

$\longrightarrow$

7 HE MOTIVATIONAL CONSTRAINT on normative reasons says that a consideration is a normative reason for an agent to act only if it is logically act. act. ${ }^{1}$ The claim figures Zelig-like in philosophical debates about practical reasons: on hand, occasionally prominent, but never the focus of discussion. However, because it is entailed by a number of prominent views about normative reasons - including various forms of internalism and some views that closely connect reasons to good practical reasoning — its truth or falsehood has important implications. ${ }^{2}$

Mark Schroeder and Julia Markovits have recently criticized the motivational constraint on the grounds of "elusive reasons": reasons for some agent to act that are such that it is logically impossible both that they are normative reasons for that agent and the agent is moved to act for those reasons. ${ }^{3}$ The type of elusive reason most discussed in the literature is what I call "blindspot reasons." Blindspot propositions are contingently true propositions that some agent cannot- "cannot" denoting logical impossibility-believe truly. ${ }^{4}$ Some of these propositions seem to be reasons for action. In Schroeder's example, Nate likes surprise parties, but only if they are a genuine surprise; thus, the fact that there is a surprise party in the living room seems like a reason for Nate to go into the living room. This reason is also a blindspot proposition for Nate. He cannot truly believe that there is a surprise party in the living room since, if he did, it would

1 Most discussions of elusive reasons say that any reason for action requires the logical ability to act for that reason, but I will use the weakened version requiring mere motivation to act for that reason. The principal reason for this is that, on the weakened formulation, it is clear how the motivational constraint is logically entailed by some common claims about normative reasons.

2 See section 4 for a discussion of these views.

3 Schroeder, Slaves of the Passions; and Markovits, Moral Reason.

4 Sorenson, Blindspots. 
not be a surprise. So, that fact is a blindspot reason for Nate. In general, a blindspot reason $p$ is a normative reason for $A$ to $\phi$ that is such that there is no possible world in which (a) $A$ believes that $p$ and (b) $p$ is true. But two plausible assumptions make this kind of reason challenging for the motivational constraint: that normative reasons are facts or true propositions, and that being moved to act for a reason $p$ requires believing that $p .{ }^{5}$ Given these assumptions, blindspot reasons fail to satisfy the motivational constraint. If Nate is moved to go into the living room because there is a surprise party in the living room, then there is no longer a reason for him to go into the living room.

In response to this criticism, a number of philosophers have attempted to reconcile blindspot reasons with the motivational constraint. Neil Sinclair claims that given a certain plausible conception of "being moved to act for a reason," blindspot reasons present no difficulty for the motivational constraint. ${ }^{6}$ Michael Ridge and Sean McKeever argue that, for any blindspot reason, there is a consideration identical to it that can satisfy the motivational constraint. ${ }^{7}$ Another defense, parts of which can be found in Ridge and McKeever and Hille Paakkunainen, claims that, for every blindspot reason, there is a consideration that bears a certain relation to that reason such that on a plausible conception of the motivational constraint the blindspot reason satisfies it. ${ }^{8}$ My aim in this paper is to show that these conciliatory strategies fail to overcome the challenge posed by elusive reasons. First, I examine each strategy and argue that it is unsuccessful on its own terms. Second, I adduce another type of elusive reason not heretofore discussed in the literature, and argue that these strategies also cannot make this kind of reason consistent with the motivational constraint. Finally, I defend the existence of this kind of reason against an important objection.

5 If reasons are worldly facts (see section 2.1), then we need a slightly different account of blindspot reasons. On this account, blindspot reasons are obtaining facts that correspond to, or perhaps make true, propositions that some agent cannot believe truly. Although I will not argue for the point here, I do not believe the assumption that normative reasons either are or correspond to true propositions is essential to the argument against the motivational constraint from blindspot reasons, although dropping that assumption would require modifying the account of blindspot reasons to some extent.

6 Sinclair, "On the Connection between Normative Reasons and the Possibility of Acting for Those Reasons."

7 McKeever and Ridge, "Elusive Reasons."

8 McKeever and Ridge, "Elusive Reasons"; and Paakkunainen, "Can There Be Government House Reasons for Action?” See section 2.2 for the formulation of Motivational Constraint*. 
1. INTERPRETING “ $A$ IS MOVED TO ACT FOR THE REASON THAT $P$ ”

\subsection{The Motivational Constraint and Motivating Reasons}

One straightforward interpretation of the motivational constraint is:

Motivational Constraint: If $p$ is a reason for $A$ to $\phi$, then there is a logically possible world $w$ in which $A$ is moved to $\phi$ for the reason that $p$.

Clearly, the key notion in this formulation is " $A$ is moved to $\phi$ for the reason that $p$." Traditionally, the locution has performed double duty, standing for the concept of being moved for a motivating reason and being moved for a motivating reason that is also a normative reason. ${ }^{9}$ More precisely: sometimes the claim that " $A$ is moved to $\phi$ for the reason that $p$ " is true just in case

1. A believes that $p$,

2. $A$ regards $p$ as a reason to $\phi$, and

3. the attitudes described in 1 and 2 nondeviantly cause $A$ to be moved to $\phi$.

Notice that, on this interpretation, $p$ need not be a normative reason for $A$ to $\phi$. This interpretation is equivalent to the semi-technical locution, "A motivating reason for $A$ to $\phi$ is $p$." Thus, I will call this the "Motivating Reason" interpretation of " $A$ is moved to $\phi$ for the reason that $p$." Sometimes, however, this locution is true just in case

1. $p$ is a normative reason for $A$ to $\phi$,

2. $A$ believes that $p$,

3. $A$ regards $p$ as a reason to $\phi$, and

4. the attitudes described in 2 and 3 nondeviantly cause $A$ to be moved to $\phi$.

On this interpretation, one of A's motivating reasons for $\phi$-ing, $p$, must also be a normative reason for $A$ to $\phi .{ }^{10}$ Call this the Motivating + Normative $(\mathrm{M}+\mathrm{N})$ interpretation of " $A$ is moved to $\phi$ for the reason that $p$."

Now, on the Motivating Reason interpretation, blindspot reasons are not counterexamples to Motivational Constraint. On this interpretation, Motiva-

9 Cf. Sinclair, "On the Connection between Normative Reasons and the Possibility of Acting for Those Reasons," 1218; McKeever and Ridge, "Elusive Reasons," 130-33.

Some formulations of the $\mathrm{M}+\mathrm{N}$ interpretation include that $p$ is true as an additional condition (see, e.g., Sinclair, "On the Connection between Normative Reasons and the Possibility of Acting for Those Reasons," 1219). I am assuming here that if it is true that $p$ is a normative reason for $A$ to $\phi$ in $C$, then $p$ is true. See note 5 for further discussion. 
tional Constraint would simply assert that the fact that $p$ is a normative reason for $A$ to $\phi$ entails that there is some possible world in which $A$ is moved to $\phi$ for the reason that $p$, but $p$ need not be a normative reason for $A$ to $\phi$ in that world. But the tension between Motivational Constraint and blindspot reasons followed from the assumption that in the possible world in which $A$ is moved to $\phi$ for the reason that $p, A$ both believes that $p$ and $p$ is a normative reason to $\phi$ (hence, $p$ is true; see note 10). If the latter assumption is dropped, then there is no difficulty reconciling blindspot reasons and Motivational Constraint. For example, the world in which Nate is motivated to go into the living room by the reason that there is a surprise party in the living room may be a world in which that consideration is not a normative reason for him to act; but this world still satisfies the description of the possible world described in the consequent of Motivational Constraint with the Motivating Reason interpretation of " $A$ is moved to $\phi$ for the reason that $p$ " plugged in.

However, it is implausible to interpret Motivational Constraint's being moved to act for reasons clause along the lines of the Motivating Reason interpretation. If we did, Motivational Constraint would probably be trivially true: any consideration could, in some set of circumstances, move an agent to act. The point of Motivational Constraint is to put a constraint on normative reasons: it is to assert that normative reasons, as such, must be capable of motivating. By contrast, Motivational Constraint on the Motivating Reason interpretation merely asserts that propositions that are normative reasons in the actual world can motivate in some possible world. Put another way, Motivational Constraint should be read as a de dicto claim: it says that, necessarily, a normative reason as such must be able to motivate. Motivational Constraint on the Motivating Reason interpretation is a de re claim: it says that if some proposition counts as a normative reason, then, necessarily, that proposition must be able to motivate.

Thus, we should opt for the $\mathrm{M}+\mathrm{N}$ interpretation of " $\mathrm{A}$ is moved to $\phi$ for the reason that $p$ " in the consequent of Motivational Constraint. Of course, if we opt for this interpretation, then we are immediately confronted with the problem of elusive reasons. On this interpretation, it is a requirement of the truth conditions for " $A$ is moved to $\phi$ for the reason that $p$ " that $p$ is a normative reason for $A$ to $\phi$ and $A$ believes that $p$, and it is precisely this combination of conditions that seems to be ruled out in the case of blindspot reasons. ${ }^{11}$ en suggests two lines of argument in this vein: first, that apparently elusive reasons are not reasons for action, but reasons of another kind; and second, that our intuitions about cases of elusive reasons track other normative phenomena, such as other reasons that are accessible to the agent ("Can There Be Government House Reasons for Action?" 58). The only 


\subsection{Neil Sinclair's Strategy}

Neil Sinclair's contribution to this debate is to suggest that there is another plausible interpretation -indeed, multiple possible interpretations - of " $A$ is moved to $\phi$ for the reason that $p$." On his favored interpretation, " $A$ is moved to $\phi$ for the reason that $p$ " means that:

1. $p$ is a normative reason for $A$ to $\phi$,

2. some agent, $X$, believes that $p$ and regards $p$ as a reason for $A$ to $\phi$ (where it is possible that $X \neq A$ ), and

3. the attitudes described in 2 nondeviantly cause $A$ to be moved to $\phi .{ }^{12}$

The key point is that, on this view, " $A$ is moved to $\phi$ for the reason that $p$ " does not entail that $A$ believes that $p$ or regards $p$ as a reason to $\phi$; rather, it entails merely that someone holds these attitudes. Call this the Proxy $M+N$ interpretation. The heart of Sinclair's argument for this interpretation is a modified version of Schroeder's case in which another person, LeTrain, believes that there is a surprise party in the living room and believes that this fact is a reason for Nate to go into the living room, but chooses to tell Nate only that there is a reason for him to go into the living room. As Nate trusts LeTrain, he acquires the belief that there is reason for him to go into the living room on the basis of LeTrain's testimony. This belief then moves him to go into the living room. Sinclair asserts that, in this case, Nate is moved to go into the living room for the reason that there is a surprise party in the living room.

How does Sinclair's proposed conception of being moved to act for a reason help resolve the problem of elusive reasons? If there is some logically possible world in which a reliable advisor is motivated by Nate's blindspot reason to advise Nate appropriately, and if in this world that advice nondeviantly causes Nate to be moved to go into the living room, then on the Proxy $M+N$ interpretation of " $A$ is moved to $\phi$ for the reason that $p$," in that world Nate is moved to go into the living room for his blindspot reason. If it is logically possible for Nate to

response I can give here is to point out that, on any of the most prominent accounts of normative reasons, elusive reasons plausibly count as such. For example, given that he enjoys surprise parties, the fact that there is a surprise party in the living room certainly seems to count in favor of Nate's going into the living room. It is also a fact that helps explain why going into the living room would promote one of his desires, or help realize something that is valuable for Nate, such as non-perverse enjoyment.

See Sinclair, "On the Connection between Normative Reasons and the Possibility of Acting for Those Reasons," 1221. Sinclair adds another condition: that the attitudes described in 2 and 3 are appropriately sensitive to the fact involved in 1 . Nothing I will say hinges on this additional condition. 
be moved to act for his blindspot reason, then Nate's blindspot reason satisfies Motivational Constraint. There seems to be nothing logically inconsistent about such an advisor playing this motivational role; so, assuming Proxy $M+N$, Nate's blindspot reason satisfies Motivational Constraint. If something analogous is true for every blindspot reason, then Sinclair has a perfectly general strategy for reconciling Motivational Constraint with blindspot reasons.

Sinclair's principal argument for the Proxy $M+N$ interpretation is that Nate's act of going into the living room on the basis of LeTrain's testimony is dependent on a sequence of mental processes that can plausibly be considered an instance of non-defective reasoning in which the fact that there is a surprise party in the living room figures as a premise. The nature of the dependence of Nate's act on this reasoning is roughly as follows: LeTrain's belief that there is a surprise party in the living room and his belief that this fact is a reason for Nate are premises in a piece of practical reasoning motivating LeTrain to act; these beliefs are nondeviantly causally connected to Nate's action, and they are sensitive both to the truth and the "reasonhood" of that fact, where "sensitivity" is a matter of the truth of certain counterfactuals. Sinclair suggests that if Nate's action is dependent in this way upon an instance of non-defective reasoning in which his blindspot reason figures as a premise, this is sufficient to establish that Nate is moved to act for that reason.

Arguably, this line of reasoning has some counterintuitive consequences. Suppose that Nate and LeTrain, who are roommates, are out on the town the night before the surprise party, which is to take place the following morning. Sometime past midnight, LeTrain decides that it is time to get home; if they are out too late, Nate will oversleep and miss his party. Nate refuses. LeTrain knows that, in his drunken state, Nate will likely fall asleep as soon as he gets homemore precisely, as soon as he flops onto the sofa—but he needs to induce Nate to agree. So, LeTrain tricks him: he calls an Uber and, as it arrives, tells Nate they are heading to another bar, not home. Nate enthusiastically jumps into the Uber. Of course, the real destination is home. Given that getting a decent night's sleep is necessary for Nate to enjoy his surprise party, the fact that getting into the Uber will take Nate home is reason for him to get into the Uber. Yet Nate's motivating reason to get into the Uber is that doing so will take him to another bar. Since the propositions that the Uber will take Nate home and the Uber will take Nate to a bar are contraries, his motivating reason contradicts his normative reason. Yet Sinclair would have us believe that because LeTrain's reasoning involving the belief that the Uber will take Nate home nondeviantly causes Nate 
to get into the Uber, Nate gets into the Uber for the reason that it will take him home. But this is at the very least a very odd way of talking. ${ }^{13}$

Sinclair also argues that if the fact that there is a surprise party in the living room is not the reason for which Nate is moved to go into the living room, then its role in bringing about that outcome must be understood either as a form of causal explanation or as an explanation in terms of motivating reasons. However, both of these options are unsatisfactory. The merely causal explanation cannot account for the role of this consideration in someone's reasoning, and the motivating reason explanation is not available because in order for some fact to be a motivating reason for some agent, that agent must believe that fact. Sinclair argues that this explanatory problem can easily be resolved if we hold that Nate is moved to act for this reason in the Proxy $\mathrm{M}+\mathrm{N}$ sense, so his being moved to act for a normative reason does not require that he doxastically grasp that reason. However, another way of accounting for the blindspot reason's deliberative and motivational roles is to characterize it as a reason for which LeTrain is moved to act in the $\mathrm{M}+\mathrm{N}$ sense. On this account, the fact that there is a surprise party in the living room is a reason for which LeTrain is moved to tell Nate that there is reason for Nate to go into the living room. This consideration plays a particular role in LeTrain's reasoning, so it is not a mere cause of his behavior; LeTrain believes this reason, so it can play the role of a motivating reason; and it is a normative reason for him to do something, namely, to tell Nate that there is a reason for him to go into the living room. On the basis of his belief that LeTrain is a reliable source, Nate acquires the belief that there is a reason for him to go into the living room - a belief that refers to his blindspot reason. This belief is his motivating reason to act accordingly. The story I have just told does not require us to claim that Nate was moved to act for his blindspot reason, yet it fully accounts for the role of his blindspot reason in reasoning and motivation.

\subsection{The Theoretical Fitness of $M+N$ and Proxy $M+N$ Interpretations}

Partly because " $A$ is moved to $\phi$ for the reason that $p$ " is a semi-technical locution, I very much doubt that my dispute with Sinclair can be resolved on the basis of intuitions: the choice between the $\mathrm{M}+\mathrm{N}$ or Proxy $\mathrm{M}+\mathrm{N}$ interpretations seems to be a matter of conceptual legislation rather than joint carving. The best way to proceed, then, is to consider the roles that the idea of being moved to act for a

13 This case is in some respects similar to a case discussed by McKeever and Ridge ("Elusive Reasons") involving a conservative who acts on the basis of a reliable liberal friend's advice to give to a cause that he would balk at if he knew more about it. I believe my case is stronger because it involves not just a normative reason that the agent would reject, but a motivating reason that formally contradicts the agent's normative reason. 
reason play in philosophical theorizing, and then to consider which interpretation of that idea is better suited to play them. I will consider two important areas in which the concept of being moved to act for a reason plays an important theoretical role: theories of moral creditworthiness and theories of rational action. I will then argue that the $\mathrm{M}+\mathrm{N}$ conception is better suited to these theoretical roles than the Proxy $\mathrm{M}+\mathrm{N}$ interpretation.

One area where the concept of acting for a reason plays an important role is in theorizing about the conditions of the creditworthiness of actions, a broad evaluative category of which the moral worth of actions is a species. Roughly, to say that a person is creditworthy for some action is to say that the action reflects well on them from some point of view-prudential, moral, etc. In the moral domain in particular, it is a familiar idea that people can do the morally right thing without being morally creditworthy for it, so moral creditworthiness requires something in addition to doing the morally right thing. A standard move is to claim that, for moral creditworthiness, one must not only act rightly but must also "act for the morally right reasons"; as Kant put it, one must not merely act in accordance with one's moral reasons, but also from them. ${ }^{14}$ Given that acting for one's moral reasons entails being moved to act for one's moral reasons, we could offer the following account of moral creditworthiness:

Moral Creditworthiness: $A$ is morally creditworthy for $\phi$-ing iff $A \phi s$ as a result of being moved to $\phi$ for the morally right reason(s).

The question is: What interpretation of "being moved to act for reasons" is the best candidate for cashing out the notion of being moved to act for the morally right reasons in Moral Creditworthiness? Suppose we opt for Sinclair's Proxy $\mathrm{M}+\mathrm{N}$ interpretation. The problems for this suggestion emerge if we consider a modified Nate and LeTrain case. Suppose that there is an evil demon who will seriously injure someone if Nate is not surprised by a surprise party in the next thirty minutes, and LeTrain knows this. Luckily, there is a surprise party in the living room. LeTrain, regarding this fact about the demon's conditional intention as a reason for Nate to go into the living room, tells Nate there is reason for him to go into the living room. However, he does not say that there is a moral reason for him to do so. Nate goes into the living room as a result of being moved to do so by LeTrain's testimony. By the lights of the Proxy $M+N$ interpretation, Nate is moved to go into the living room for the reason that the demon conditionally intends to injure someone. Thus, Nate has done the thing he morally ought to have

14 For discussion, see Arpaly, "Moral Worth”; Stroud, "Moral Worth and Rationality as Acting for Good Reasons"; Markovits, "Acting for the Right Reasons"; and Way, "Creditworthiness and Matching Principles." 
done, and he did it because he was moved to act for the morally right reason. According to Moral Creditworthiness, Nate is therefore morally creditworthy for going into the living room-despite having no idea that anything morally significant was at stake in doing so! Something has gone awry.

One widely accepted way of cashing out the notion of acting for the morally right reasons is that one's motivating reasons must match one's moral reasons. This yields the following account of moral creditworthiness:

Matching Reasons: $A$ is morally creditworthy for $\phi$-ing iff the motivating reasons for which $A$ is moved to $\phi$ (and subsequently $\phi s$ ) are the moral reasons for $A$ to $\phi{ }^{15}$

Notice that this account of creditworthiness uses the $\mathrm{M}+\mathrm{N}$ concept of being moved to act for a reason. The account basically claims that one is morally creditworthy for an action only in case one is moved to act for a reason-in the $\mathrm{M}+\mathrm{N}$ sense-that is a moral reason for one so to act. ${ }^{16}$ Thus, in many discussions of moral creditworthiness, the operative conception of being moved to act for reasons is the $\mathrm{M}+\mathrm{N}$ conception, not the Proxy $\mathrm{M}+\mathrm{N}$ conception. Furthermore, if the idea of an agent's motivating reasons matching her normative reasons is key to interpreting "being moved to act for the morally right reasons" as a necessary condition of creditworthiness, then Sinclair's conception is arguably not suitable for the following reason. The Proxy $\mathrm{M}+\mathrm{N}$ interpretation would count someone as being moved to act for a normative reason even when their motivating reasons do not match their normative reasons, and a fortiori do not match their moral reasons. In the Nate and LeTrain case, Nate's reason for being moved to act is something like that there is a reason for me to act, or perhaps that LeTrain, a reliable and virtuous friend, told me there is a reason for me to act. Arguably, neither fact is a normative reason for Nate to act. Sinclair argues that counting the former as a normative reason in its own right leads to an infinite regress, and Ridge and McKeever argue that facts about testimony are never themselves normative reasons. ${ }^{17}$ Even if they are normative reasons for Nate to act, neither is the same reason as that the demon conditionally intends to injure someone. Thus, if Matching Reasons captures something crucial about the idea of being moved to act for the morally right reasons, it is not plausible to cash out the latter in terms of Sinclair's conception of being moved to act for a reason.

15 For discussion, see Markovits, "Acting for the Right Reasons"; Way, "Creditworthiness and Matching Principles."

This is a merely necessary condition, since for moral creditworthiness one has to actually act in addition to being moved to act for the right reason.

McKeever and Ridge, “Elusive Reasons," esp. 116-20. 
Not everyone accepts that acting for the morally right reasons is sufficient for moral creditworthiness. ${ }^{18}$ The details of the arguments against the sufficiency of the consequent of Moral Creditworthiness need not occupy us here. The important thing for our purposes is that if satisfying the consequent of Moral Creditworthiness is not sufficient for moral creditworthiness, this gives Sinclair an opening to claim that the concept of being moved to act for reasons and the concept described on the right side of the biconditional in Matching Reasons are distinct concepts, rather than the latter being a way of cashing out the former. In this way, Sinclair might claim that being moved to act for reasons can be understood along the lines of his conception without yielding counterintuitive results. We can call the resulting account Moral Creditworthiness*:

Moral Creditworthiness*: $A$ is morally creditworthy for $\phi$-ing iff (1) $A$ is moved to $\phi$ (and subsequently $\phi s$ ) for the morally right reason(s) and (2) the motivating reasons for which $A$ is moved to $\phi$ are the moral reasons for $A$ to $\phi{ }^{19}$

This account would not yield that Nate is morally creditworthy if he acts on LeTrain's vague advice. Instead, it would say that Nate acts for the morally right reasons, but his motivating reasons do not match those reasons, so Nate is not morally creditworthy. Thus, while an account of moral creditworthiness using Sinclair's conception would not necessarily yield counterintuitive verdicts, amending the account so as to eliminate these verdicts would commit him to saying that someone might fulfill the condition of being moved to act for the morally right reasons even if her motivating reasons do not match her normative reasons. The matching requirement would be a further requirement on creditworthiness, rather than an interpretation of the concept of being moved to act for the right reasons.

However, this move is foreclosed for Sinclair by the idea that the moral creditworthiness of action must not depend on luck. I will presently argue that, for this reason, Sinclair's conception is unsuited to play the role in theorizing about

Cf. Way, "Creditworthiness and Matching Principles." It is unclear to me whether in making his case against the sufficiency of Matching Reasons, Way intends to show that acting for the morally right reasons is not sufficient for creditworthiness, or that his "Matching Principles" is a rival interpretation of "Acting for the morally right reasons." Way seems to suggest that he is open to rejecting the equation of moral creditworthiness and acting for the morally right reasons ("Creditworthiness and Matching Principles," 213n9).

Given that the case against the sufficiency of Moral Creditworthiness may turn on the claim that Matching Reasons is not sufficient for moral creditworthiness - thus, it assumes that Matching Reasons is an interpretation of "acting for the morally right reasons"-this revised account would probably require an additional condition, such as Way's Matching Principles. 
moral creditworthiness even if it does not entail counterintuitive verdicts about cases.

One plausible desideratum of any account of moral creditworthiness is that one's moral creditworthiness for an action does not depend to a significant degree upon luck. As Jonathan Way puts it, "You are not creditworthy for a response if the way in which that response was motivated could quite easily have led you to do the wrong thing." ${ }^{20}$ Given this "no-luck" constraint, and assuming that being moved to act for the morally right reasons is at least a necessary condition on moral creditworthiness, a conception of being moved to act for the right reasons must foreclose the possibility of being moved to act for the right reasons accidentally. Sinclair's conception does not do this. On his view, a person may be moved to act for the morally right reasons if there happens to be a reliable and virtuous advisor who, grasping those reasons, is able to advise the agent to act without describing the reasons that support acting this way and chooses to do so. Surely, the advisee could quite easily have done the wrong thing: she might not have followed the advice properly, and the advisor might not have been on hand, might not have been able to advise properly, or might not have chosen to give advice. ${ }^{21}$ But then this conception of being moved to act for reasons makes moral creditworthiness depend on luck, in violation of the no-luck constraint.

Another area of philosophical inquiry in which the idea of being moved to act for reasons plays an important role is theories of "rational agency," the conditions under which it is rational for agents to act. The relationship between rationality and reasons is a matter of significant debate, but suppose that something like the following is true:

Rationality and Reasons (RR): $A \phi$-ed rationally only if $A$ had reasons that made it reasonable for $A$ to $\phi$ and $A$ was moved to $\phi$ "for" some (sub-)set of those reasons. ${ }^{22}$

The concept of being moved to act for a reason appears in this claim as a necessary condition on the ex post rationality of an action. ${ }^{23}$ Let us consider how Sin-

20 Way, "Creditworthiness and Matching Principles," 218.

21 As I mentioned in note 12, Sinclair includes in Proxy $M+N$ the condition that X's attitudes are appropriately sensitive to, because counterfactually dependent upon, the fact that $p$ is a normative reason for $A$ to $\phi$. This condition rules out the possibility of the advisor making certain kinds of mistakes, such as being mistaken about whether $p$ is a genuine normative reason for $A$. It does not, however, rule out the possibilities described here. Thus, $A$ 's being moved to $\phi$ as a result of the advisor's testimony might still be objectionably lucky.

This is Comesaña and McGrath's formulation of the relation between rationality and reasons ("Having False Reasons," 62).

23 For the distinction between ex post and ex ante judgments of rationality, see Comesaña and 
clair's conception of being moved to act for a reason fares in this role. Since RR offers only a necessary condition of rational action, we do not encounter quite the same problems as we did in the case of Moral Creditworthiness. ${ }^{24}$ Yet the same basic point applies here: even if satisfying RR does not make an action rational, it is obscure exactly how the fact that someone else grasped the normative significance of, and was motivated by, A's reasons is supposed to help satisfy a condition of the rationality of A's action. Consider again the case involving LeTrain and Nate having a night on the town. LeTrain has told Nate that the Uber will take them to the next bar, when in fact, it will take them home. Suppose that the consideration that the Uber will take him to the next bar is not a reason for Nate to get into the Uber because it is false; furthermore, even if it were true, it would not be a reason to get into the Uber because going to the next bar would not fulfill any of Nate's reflective non-perverse preferences and is not morally required. On RR together with the $\mathrm{M}+\mathrm{N}$ conception of acting for reasons, $\mathrm{Na}$ te's getting into the Uber for this reason should turn out to be irrational, as it is not based on -in the sense of "based on" meaning "motivated by"-any real or apparent normative reason. Rather, it is based on a false proposition that, even if true, would not provide a reason for Nate to act. And this seems to be the most intuitive verdict on this case: Why, after all, should we credit Nate for acting rationally when, for all he believed, his action was not recommended even by any consideration that would be a normative reason to act if it were true? By contrast, on Sinclair's conception, Nate's getting into the Uber would not turn out to be irrational even if none of his beliefs genuinely supported acting in that way, since he would nevertheless be moved to act for the normative reason that the Uber will get him home. Again, this just does not seem right. It is not Nate who has the beliefs in the light of which getting into the Uber is rational; it is LeTrain.

The general point is this: whichever way we wish to spell out the rationality of action, to say that an action is "rational" is to say something about the relation between the action and the agent's view about the circumstances under which she acted. ${ }^{25}$ But using Sinclair's conception as a way of cashing out the concept of being moved to act in light of some beliefs would commit us to saying that, in

McGrath, "Having False Reasons," 61.

24 For the different view that rational action is action for good reasons or apparent reasons, see Parfit, "Rationality and Reasons." For the view that rational action is action on good reasons but not for them, see Arpaly, Unprincipled Virtue.

25 Stroud makes precisely this point to criticize Arpaly's account of rationality in Unprincipled Virtue: "I myself am very loath to accept [contra Arpaly] ... that an agent's beliefs about and evaluation of the reasons in favor of options $A$ and $B$ are irrelevant to the rationality of her opting for (say) B" ("Moral Worth and Rationality as Acting for Good Reasons," 454). 
some cases, the beliefs that make the action rational, and in the light of which the agent was moved to act, do not in any way represent the agent's view about the circumstances under which she acted. So, to call an action "rational," on this conception, would not necessarily say anything about the relation between the action and the agent's view about the circumstances under which she was moved to act. At that point, it is tempting to say that we would be no longer talking about rationality, or at least not about the concept of rationality with which the theory of rational agency is typically concerned.

I have shown that Sinclair's conception of acting for a reason is not best suited to two important theoretical roles for which the concept of being moved to act for a reason is used. Of course, it is open to Sinclair to grant this point and reply that there is no conclusive reason to think that we must use the same conception of being moved to act for a reason in every theoretical area. This is true, and I do not intend these considerations of theoretical fit as a knockdown argument. Still, if the $\mathrm{M}+\mathrm{N}$ conception is operative in all other areas in which the concept being moved to act for a reason figures, or at least if the Proxy $\mathrm{M}+\mathrm{N}$ conception is never operative in these areas, then the burden of proof is on Sinclair to show that the $\mathrm{M}+\mathrm{N}$ conception is not operative, or at least that the Proxy $\mathrm{M}+\mathrm{N}$ conception is operative, in Motivational Constraint.

\section{A DIFFERENT REASON?}

\subsection{Identical Reasons}

Ridge and McKeever propose a different solution to the problem of elusive reasons. Like Sinclair, they claim that the logical possibility of a reliable advisor playing a certain role in causing Nate to be moved to go into the living room can help blindspot reasons satisfy Motivational Constraint. However, according to them, in the Surprise Party case involving LeTrain there is a normative reason for which Nate is moved to act in the $\mathrm{M}+\mathrm{N}$ sense; hence, contra Sinclair, Nate's motivating reason is also $a$ normative reason. Furthermore, they argue that, assuming reasons are a certain kind of coarse-grained fact, this reason - the reason for which Nate is moved to act in the $\mathrm{M}+\mathrm{N}$ sense-is identical to Nate's blindspot reason. Hence, Nate's blindspot reason satisfies Motivational Constraint after all.

Some of what follows hinges on the distinction between facts understood as states of affairs - complexes of concrete individuals, objects, and properties that obtain - and true propositions understood as structured complexes of concepts that are true. Many share the view that reasons are facts rather than true propositions, although there appears to be nothing approaching a consensus on 
the matter. ${ }^{26}$ I will not assume that reasons are either facts or true propositions for the purposes of this paper; my only assumption is that the object of belief is a proposition, not a fact. Except where noted, when I use the word "fact" to describe or refer to a reason for action, this can be taken to mean either a true proposition or an obtaining state of affairs. I will use the term "worldly fact" to designate only obtaining states of affairs.

According to Ridge and McKeever, in the Nate and LeTrain case one normative reason for Nate to go into the living room is the fact that his so doing will promote the worthy end(s) that his friend's advice is actually tracking. I will call this the "R\&M reason." I do not deny that this fact is a normative reason for Nate to go into the living room or that it is not a blindspot reason for Nate; from this it follows that it could be a reason for which Nate is moved to act in the $\mathrm{M}+\mathrm{N}$ sense. While thus far we have been referring to the fact that there is a surprise party in the living room as Nate's blindspot reason, Ridge and McKeever actually point to another blindspot reason in the Surprise Party case: that Nate will be pleasantly surprised if he goes into the living room. For them, this reason bears the relation of "Russellian identity" to the R\&M reason. As I define this notion,

Russellian Identity: Two reasons $p$ and $q$ are Russellian identical iff

1. $p$ and $q$ are worldly facts and $p$ is identical to $q$, or

2. $p$ and $q$ are propositions and $p$ and $q$ correspond to or are made true by the same worldly fact.

Understood as worldly facts, going into the living room will promote the worthy end(s) that Nate's friend's advice is actually tracking is the same worldly fact as Nate will be pleasantly surprised if he goes into the living room; understood as true propositions, they correspond to the same worldly fact. So, Ridge and McKeever argue that the R\&M reason is Russellian identical to one of Nate's elusive reasons. $^{27}$

Sometimes the distinction is obscured by the equivocal use of the term "fact." For example, T.M. Scanlon says that reasons are facts, but by "facts" he means "reflections of true thoughts." On this understanding of "fact," Scanlon is closer to those who believe that reasons are true propositions. Dancy says that reasons are "facts, or, better, states of affairs," but by "facts" he means what I mean by "worldly facts," with the important qualification that he may think some states of affairs that do not obtain are reasons. See Scanlon, Being Realistic about Reasons; and Dancy, Practical Reality, esp. 116.

What about the reason that is the target of Sinclair's discussion, that there is a surprise party in the living room? McKeever and Ridge could plausibly identify a reason similar to the R\&M reason that is Russellian identical to that elusive reason: for example, that there is something in the living room that explains why Nate's going into the living room will promote the worthy end(s) that his friend's advice is actually tracking. If what I say below is correct, then McKeever 
Although the relation of Russellian identity can hold between worldly facts or propositions, it is actually important to Ridge and McKeever's argument that reasons are worldly facts rather than true propositions. On this assumption, any two Russellian identical reasons are identical reasons. So, if reasons are worldly facts, then the R\&M reason and one of Nate's elusive reasons-that Nate will be pleasantly surprised if he goes into the living room-are identical reasons. Ridge and McKeever argue that if these reasons are identical then when Nate is moved to act for the reason that going into the living room will promote the worthy end(s) that Nate's friend's advice is actually tracking, it follows that he is moved to act for the reason that he will be pleasantly surprised if he goes into the living room. If that is true, then the latter satisfies Motivational Constraint: Nate's being moved to act for the R\&M reason just is his being moved to act for the blindspot reason. So, on the assumption that reasons are worldly facts, Ridge and McKeever appear to have a plausible strategy for reconciling Motivational Constraint with blindspot reasons. If, on the other hand, reasons are true propositions, then Ridge and McKeever's solution fails. If reasons are true propositions, then even if the $R \& M$ reason and the elusive reason are Russellian identical, they are not identical reasons. Thus, on the view that reasons are true propositions, the fact that one is moved to act for the R\&M reason does not entail the fact that one is moved to act for the blindspot reason.

In fact, I believe that, even assuming that reasons are worldly facts and the $R \& M$ reason is the same worldly fact as the elusive reason, it does not follow that when Nate is moved to act for the R\&M reason, he is moved to act for the elusive reason. Recall that the $\mathrm{M}+\mathrm{N}$ interpretation requires that the agent possess two propositional attitudes: the belief that $\langle p\rangle$ and the attitude of regarding $\langle p\rangle$ to be a reason $(<p>$ is the proposition that $p)$. The fact that being moved to act for the reason that $p$ ought to be analyzed in terms of these two propositional attitudes plus their causal role in bringing about an action, along with the fact that propositions are generally taken to be the referents of that-clauses, suggests that a proposition is the referent of the clause "the reason that" in the statement " $A$ is moved to $\phi$ for the reason that $p$." In claiming this, I am not simply insisting, contra Ridge and McKeever, that normative reasons are propositions and not worldly facts. From the claim that " $p$ " in the statement " $A$ is moved to $\phi$ for the reason that $p$ " is the proposition $\langle p\rangle$, it does not follow that the term "reason" exclusively refers to propositions. Consider the fact that the referent of "the belief that" is a proposition, yet this does not entail that the term "belief" exclusive-

and Ridge's strategy for solving the problem of elusive reasons fails for any elusive reason and not just the one that is the target of their discussion. 
ly refers to a proposition. ${ }^{28}$ Now, although the proposition $<$ he will be pleasantly surprised if he goes into the living room $>$ may be Russellian identical to the proposition < going into the living room will promote the worthy end(s) that my friend's advice is actually tracking $>$, they are not identical propositions: they clearly consist of different concepts. It follows that the fact that one is moved to act for the reason that $<$ he will be pleasantly surprised if he goes into the living room $>$ neither entails, nor is entailed by the fact that one is moved to act for the reason that < going into the living room will promote the worthy end(s) that my friend's advice is actually tracking $>$. Therefore, even assuming that reasons are worldly facts, establishing that the R\&M reason and Nate's blindspot reason are the same worldly facts is not sufficient to establish that being moved to act for the $R \& M$ reason entails being moved to act for the blindspot reason. Thus, Ridge and McKeever's strategy does not ensure that Nate's blindspot reason satisfies Motivational Constraint. A fortiori, it fails as a general strategy for reconciling blindspot reasons with Motivational Constraint.

It may be objected that my argument against Ridge and McKeever's strategy depends upon the particular wording I have chosen for Motivational Constraint. That wording includes the phrase " $A$ is moved to $\phi$ for the reason that $p$," and in that phrase $p$ plausibly refers to a proposition. But suppose we reworded Motivational Constraint as the claim that if $p$ is a reason for $A$ to $\phi$, then there is a logically possible world $w$ in which $A$ is moved to $\phi$ because $p$. There, $p$ plausibly refers to a worldly fact. ${ }^{29}$ My response to this is that "because $p$ " is ambiguous as between a purely causal reading and a motivational reading. On the causal reading, $p$ refers to a worldly fact: we might say, for example, that I went to bed early because I took melatonin, which made me feel sleepy. But "because $p$ " could also have a motivational reading, according to which $A$ is moved to $\phi$ because $A$ believed that $p$ and regarded $p$ as a reason to $\phi$, and these attitudes nondeviantly caused him to be moved to $\phi$. On this reading, $p$ refers to a proposition. For example, I might say that Lois Lane climbed to the rooftop of the building because Superman was there. Even if that is true, it might yet be false that Lois Lane climbed to the rooftop of the building because Clark Kent was there. This suggests that, in this use of the locution "because p," Superman is there is the propositional object of some attitudes in the light of which, and because of

Nevertheless, it does suggest that, like "belief," which sometimes refers to an attitude and sometimes to the propositional object of that attitude, "reason" must at least sometimes refer to propositions, even if normative reasons - reasons that count in favor of acting-are all worldly facts. This yields a disjunctive view of reasons in some ways similar to that proposed by Hornsby, "A Disjunctive Conception of Acting for Reasons." 
which, Lois Lane performed the action. And it seems to me that everyone in this debate, including Ridge and McKeever, interpret Motivational Constraint using the motivational reading, regardless of whether they use the "for the reason that $p$ " or "because $p$ " locutions. If that is true, then the suggested rewording does not save Ridge and McKeever's strategy.

\subsection{The Derivative Reasons Strategy}

Another strategy for reconciling Motivational Constraint with blindspot reasons claims that a plausible conception of the Motivational Constraint allows a blindspot reason to satisfy it so long as the reason is suitably related to some other reason for which that agent can be moved to act. ${ }^{30}$ In other words, this strategy hinges on arguing for a revised version of the Motivational Constraint, which we can call Motivational Constraint*:

Motivational Constraint ${ }^{*}$ : If $p$ is a reason for $A$ to $\phi$, then there is a logically possible world $w$ in which

1. $A$ is moved to $\phi$ for the reason that $p$, or

2. $A$ is moved to $\phi$ for a reason $q$ that bears relation(s) $\mathrm{R}$ to reason $p$.

The strategy then argues that derivativeness is a relation that satisfies the second disjunct of Motivational Constraint*. To illustrate this relation using Paakkunainen's example: suppose $\phi$-ing would destroy the only crop-yielding field in a village, and destroying the field would lead to much suffering. ${ }^{31}$ Both facts seem to be decisive reasons against $\phi$-ing, but the latter seems more fundamental than the former in that the former is a reason not to $\phi$ because it stands in some important relation to the latter. Here is one possible formulation of this derivativeness relation:

Derivative Reason: A reason $p$ is derivative of a reason $q$ just in case $p$ is a reason in virtue of standing in some important relation to $q .{ }^{32}$

Aspects of this approach can be found in McKeever and Ridge, "Elusive Reasons"; and Paakkunainen, "Can There Be Government House Reasons for Action?” However, I do not want to attribute the strategy to either for a couple of reasons. McKeever and Ridge do not clearly invoke the relation of derivativeness; they use the word "parasitism," and it is unclear to me whether they mean this word to pick out what I mean by "derivativeness." And Paakkunainen's principal response to elusive reasons is to quickly cast doubt on the reality of such reasons. She invokes the idea of derivative reasons to handle another set of putative reasons that make trouble for her Deliberative Constraint. So, neither of them quite makes the argument I am laying out here.

Paakkunainen, "Can There Be Government House Reasons for Action?" 87.

This formulation can be found in Nair, "How Do Reasons Accrue?" 64-65. 
The strategy argues that the second disjunct of Motivational Constraint* is satisfied if either $q$ is derivative of $p$ or $p$ is derivative of $q$. For example, plausibly, the non-blindspot reason that Nate will be pleased if he goes into the living room is derivative of the blindspot reason that there is a surprise party in the living room, since the former is a reason in virtue of being explained by the latter. ${ }^{33}$ So, if we accept Motivational Constraint ${ }^{*}$ and that for every blindspot reason there is either (a) a non-blindspot reason for which the agent can be moved to act and from which the blindspot reason derives or (b) a non-blindspot reason for which the agent can be moved to act that is derivative of the blindspot reason, then we seem to have a way of reconciling blindspot reasons with Motivational Constraint* The argument hinges on the claims that (1) the Motivational Constraint ${ }^{*}$ is a plausible conception of the motivational constraint and (2) derivativeness satisfies the second disjunct of Motivational Constraint* It is to an evaluation of these two claims that I presently turn.

\subsection{The Argument for Motivational Constraint* and Derivativeness as a Satisfier}

The derivative reasons strategy raises the fundamental question of whether Motivational Constraint ${ }^{*}$ - and in particular, its second disjunct—is itself a plausible conception of the motivational constraint. On its face, it would seem that taking the latter seriously would rule out the second disjunct of Motivational Constraint*: if the motivational constraint is the claim that the existence of a reason implies the possibility of being moved to act for that reason, then the possibility of being moved to act for some other reason just does not cut it. However, a proponent of Motivational Constraint* has at least one argument in its favor. The argument is that an agent ought to be able to satisfy the motivational constraint with respect to a blindspot reason by being able to be moved to act for some non-blindspot reason so long as the agent's inability to act for a blindspot reason does not entail that she is unable to appropriately respond to anything of normative significance in her circumstances. Admittedly, this talk of "normative significance" is a bit wooly, so let me try to make precise-if not less metaphorical—one thing we might mean by it.

It is a familiar idea in ethics that reasons for action not only count in favor of acting, but that they do so with a certain strength or weight. We might represent these weights as natural numbers, so that any reason for action can be represented as a four-place relation between a fact $p$, an agent $A$, an action $\phi$, and a natural

33 We might argue, too, that Nate will be pleasantly surprised if he goes into the living room is derivative of the R\&M reason in virtue of helping to explain it (Nate will be pleasantly surprised if he goes into the living room is a reason because it helps to explain the fact that going into the living room will promote the worthy end that LeTrain's advice is actually tracking.) 
number $n$ : $R(p, \mathrm{~A}, \phi, n)$. In many cases, where $p$ is a reason to $\phi$ with strength $m$, and $q$ is a reason to $\phi$ with strength $n, p$ and $q$ support $\phi$-ing with a strength of $\mathrm{M}+\mathrm{N}$; the accrual of these reasons is an increasing function of the weights of the individual reasons. ${ }^{34}$ For example, that Mark promised to go to dinner at Rick's with Mel and Rick's is Mark's favorite restaurant seem to be two reasons for Mark to go to dinner at Rick's whose accrual supports that action more strongly than either of the reasons individually. I will call reasons that accrue additively in this way "independent" reasons. ${ }^{35}$ However, there are some reasons that do not accrue additively. For example, in the LeTrain case, the accrual of the reasons going into the living room will promote the worthy end(s) that Nate's friend's advice is actually tracking and there is a surprise party in the living room is not additive: the accrual of both reasons does not count in favor of going into the living room more strongly than either of these reasons individually. Similarly, the reasons that $\phi$-ing would destroy the only crop-yielding field in a village and destroying the field would lead to much suffering seem not to accrue additively. Notice, too, that, while in both examples the reasons do not accrue additively, their accrual also does not have less strength than either reason individually. ${ }^{36}$ We might therefore roughly characterize such pairs of reasons as lacking in distinct weight or strength. I will call such reasons overlapping reasons: a reason $p$ to $\phi$ with strength $m$ and a reason $q$ to $\phi$ with strength $n$ are overlapping just in case $m=n$ and the accrual of $p$ and $q$ support $\phi$-ing with strength $m .{ }^{37}$ Moreover, there are often more than two reasons that overlap one another. For example, that there is a surprise party in the living room, that Nate will be pleasantly surprised if he goes into the living room, that Nate will be pleased if he goes into the living room, and that going into the living room will promote the worthy end (s) that Nate's advice is actually tracking all seem to be reasons for Nate to act that do not have distinct strength, and so overlap. I will call any group of overlapping reasons consisting of two or more reasons a "cluster" of overlapping reasons.

Now, one proposal for cashing out the idea of "normative significance" in the argument for Motivational Constraint* is in terms of non-overlapping clusters of overlapping reasons. ${ }^{38}$ Intuitively, the idea is that all features of an agent's cir-

34 Nair, "How Do Reasons Accrue?" 63.

35 Nair, "How Do Reasons Accrue?" 63.

36 To use Nair's example, that it's hot outside and it's raining outside may together support not going for a run with less strength than either of these reasons individually ("How Do Reasons Accrue?" 59). Thus, not all nonindependent reasons are overlapping. See Nair, "How Do Reasons Accrue?"; and Lord and Maguire, "An Opinionated Guide to the Weight of Reasons," esp. 12.

38 If $S$ and $A$ are two clusters of overlapping reasons, $S$ and $A$ are nonoverlapping just in case 
cumstances that are normatively significant for her are captured by the set of distinctly weighted, or non-overlapping, reasons for her to act. ${ }^{39}$ This idea can be expressed in terms of clusters of overlapping reasons: an agent is able to be moved to act on every normatively significant feature of her circumstances if she is able to be moved to act for at least one member of all the non-overlapping clusters of her overlapping reasons. ${ }^{40}$ So, the argument for Motivational Constraint ${ }^{*}$ is as follows. So long as some reason $p$ is a member of a cluster of overlapping reasons, and an agent is able to be moved to act for one of these members, she is able to be moved to act on that normatively significant feature of her circumstances captured by $p$. And if she can do this, she ought to satisfy the motivational constraint with respect to $p$.

Having established Motivational Constraint ${ }^{*}$ with this argument, the derivative reasons strategy can invoke the notion of overlapping reasons to help clinch the argument that all blindspot reasons satisfy Motivational Constraint*. One premise of that argument that has so far not been supported is the claim that derivativeness is a relation that satisfies the second disjunct of Motivational Constraint*. The argument just offered for Motivational Constraint ${ }^{*}$ implies that one relation that does satisfy its second disjunct is the relation of "overlapping-ness." So, the derivative reasons strategy can now claim that whenever two reasons are related by derivativeness they are overlapping, thus substantiating the claim that the former satisfies the second disjunct of Motivational Constraint*. In general, if one reason derives its normative force from another, then it will have no independent normative strength or weight. This seems to be borne out in our analysis of the Surprise Party case. We said that one non-blindspot reason for Nate to go into the living room is that Nate will be pleased if he goes into the living room, and this reason is derivative of the elusive reason that there is a surprise party in the living room. Intuitively, both reasons support going into the living room with the same strength or weight, but their accrual seems to support going into the living room no more and no less than either one individually. So, they are overlapping. Thus, if Motivational Constraint* is correct; and if for every blindspot reason there is either (a) a non-blindspot reason for which the agent can act and from

there is no member of $S$ that is also a member of $A$ and vice versa.

39 For ease of exposition, this statement excludes instrumental reasons, which do overlap but are not reasons to perform the same act as the reasons that overlap with them. See Nair, "How Do Reasons Accrue?" 60.

40 Perhaps normatively significant features include facts that are not themselves reasons but affect the strength of reasons, which we call modifiers, or their instantiations, which we call defeaters and enablers. For an overview of these concepts, see Lord and Maguire, "An Opinionated Guide to the Weight of Reasons," 11. 
which the blindspot reason derives or (b) a non-blindspot reason for which the agent can act and derivative of the blindspot reason; and if all reasons related by derivativeness are overlapping, then all blindspot reasons satisfy the second disjunct of Motivational Constraint*.

\subsection{Evaluating the Argument for Motivational Constraint*}

The key idea motivating the argument for Motivational Constraint* is that all the features of an agent's circumstances that are normatively significant for her are captured by the set of distinctly weighted, or non-overlapping, reasons for her to act. For example, that Mark promised to go to dinner at Rick's with $\mathrm{Mel}$ and Rick's is Mark's favorite restaurant are non-overlapping reasons for Mark to go to dinner at Rick's, and, intuitively, they are normatively significant for Mark in a distinct way. But this is not the only way to individuate normatively significant features. For many philosophers, reasons are closely connected to explanation: for example, on the two most prominent non-fundamentalist views about reasons, reasons are facts that explain how actions promote desires or why actions have some other normative status. ${ }^{41}$ Let us assume the latter view for ease of exposition. Someone attracted to this kind of view will, I think, naturally understand the normatively significant features of an agent's circumstances in terms of the facts that explain how actions promote valuable states of affairs, and will claim that only an agent who grasps the complete explanations of how actions promote valuable states of affairs will grasp all of the normatively significant features of her circumstances. I will call this the "explanatory" notion of normative significance, as opposed to the "non-overlapping reasons" notion of normative significance. But adopting such a conception of normatively significant features will require accepting that an agent does not always grasp all of the normatively significant features of her circumstances by grasping at least one member of all the non-overlapping clusters of her overlapping reasons. In many cases, individual reasons will only be partial explanations: for example, that Nate likes surprise parties only partially explains why Nate will be pleased if he goes into the living room. That Nate likes surprise parties and that there is a surprise party in the living room are overlapping reasons, but they make distinct explanatory contributions to the fact that Nate will be pleased if he goes into the living room. As this example suggests, even overlapping reasons can constitute distinct parts of a complete explanation of the target fact. Similarly, the fact that by $\phi$-ing one will destroy the only crop-yielding field in the village overlaps with the fact that destroying the only

41 For examples, see Markovits, Moral Reason; Broome, Rationality through Reasoning; Schroeder, Slaves of the Passions; McKeever and Ridge, Principled Ethics; and Finlay, "The Reasons that Matter." 
crop-yielding field in the village would lead to much suffering, which itself overlaps with the fact that $\phi$-ing will lead to much suffering. But on theories of reasons that point up their explanatory role, the first two facts are reasons not to $\phi$ in virtue of being distinct parts of an explanation of the third fact. And since they are distinct parts of that explanation, on this view they have distinct normative significance. Thus, if we adopt the explanatory conception of normative significance, then Motivational Constraint* is not supported by the argument from normative significance.

If the argument from normative significance does not support Motivational Constraint ${ }^{*}$, then in the absence of another compelling argument for Motivational Constraint ${ }^{*}$, we ought to revert back to the conception of the motivational constraint spelled out in Motivational Constraint. So, whether or not the argument from normative significance supports Motivational Constraint ${ }^{*}$ depends upon our choice of conceptions of normative significance. I have not defended the explanatory conception over the non-overlapping reasons conception; instead, I have simply offered it as a plausible alternative, and I suspect that it is not the only one. Given this, it seems that the available arguments are insufficient to support the move from Motivational Constraint to Motivational Constraint*. I have already argued in this paper that blindspot reasons do not satisfy Motivational Constraint. Thus, the available arguments are insufficient to vindicate this strategy for reconciling blindspot reasons with the Motivational Constraint.

\section{ANOTHER ELUSIVE REASON}

So far, philosophers have only discussed blindspot reasons in print. However, there is clearly logical space available for other kinds of elusive reason. Recall Motivational Constraint:

Motivational Constraint: If $p$ is a reason for $A$ to $\phi$ in circumstances $C$, then there is a logically possible world $w$ in which (a) circumstances $C$ obtain and (b) $A$ is moved to $\phi$ for the reason that $p$.

Now recall the Motivating + Normative $(M+N)$ interpretation of " $A$ is moved to $\phi$ for the reason that $p$ ":

1. $p$ is a normative reason for $A$ to $\phi$ in $C$,

2. $A$ believes that $p$,

3. $A$ regards $p$ as a reason to $\phi$, and

4. the attitudes described in 2 and 3 nondeviantly cause $A$ to be moved to $\phi$. 
Given Motivational Constraint and the $\mathrm{M}+\mathrm{N}$ interpretation, a reason could count as elusive so long as it is logically impossible for at least two of the conditions of the Motivational Constraint or the $\mathrm{M}+\mathrm{N}$ conception to jointly obtain. Clearly, that leaves sizeable logical space for elusive reasons. In this section, I will explore only a small corner of that space. We have seen that a blindspot reason $p$ is such that, given the factivity assumption, it is logically impossible that it is a normative reason for $A$ to $\phi$ and $A$ believes that $p$. Another kind of elusive reason is a reason $p$ such that it is impossible that $p$ is a normative reason for $A$ to $\phi$ and $A$ regards $p$ as a reason to $\phi$. Here is an example of such a reason. Suppose I like to kick cans down the road, but only if I do not take myself to have any reason for doing so. Plausibly, that I like to kick cans down the road is a reason for me to kick this can. However, because as soon as I regard a consideration as a reason for me to kick this can down the road, that consideration is no longer a reason for me to do so, the fact that I like to kick cans down the road is a reason for me to act that is such that it cannot be a reason for me to act and I regard it as a reason for me to act. Therefore, it is an elusive reason.

One might object that if I only like to kick cans down the road for no reason, it is impossible for me to do what I like to do intentionally, and this might suggest that the fact that I like to kick cans down the road is not a reason for me to do so. Let us assume arguendo one of the key premises of this objection, that $p$ is a reason for $A$ to $\phi$ only if $A$ is able to $\phi$ intentionally. The other key premise is that $A$ is able to intentionally $\phi$ only if $A$ regards some consideration as a reason for $\phi$-ing. This seems like a plausible principle. But if I am assembling some IKEA furniture and I select, from among a small heap of identical screws, one particular screw, I may not pick up that screw for any reason because I may not regard any consideration as a reason for picking up that screw. ${ }^{42}$ Nevertheless, picking up that screw is surely an action I perform intentionally. Therefore, the principle that intentional action requires acting for reasons is false, at least on one interpretation of that principle.

In fact, I believe there is a plausible interpretation of this principle, but it does not support the objection. To see this, we must distinguish between action-universals (or act-types) and action-particulars. ${ }^{43}$ An action-particular is a to pick up any particular screw: namely, that my furniture requires a screw. I concede that this is a possibility. My claim is only that, in order to be properly motivated to pick up that screw, an agent need not regard any consideration as a reason to pick up that screw: she need only regard some consideration as a reason to pick up some screw. Thanks to an anonymous reviewer for the Journal of Ethics and Social Philosophy for this objection. 
concrete event that satisfies whatever conditions are necessary and sufficient for intentional action. Such actions are typically denoted by sentences like "Jones shot Smith," "Anna turned on the lights," and "Sully landed the plane." On the other hand, an action-universal is a type of intentional action; we denote such actions using phrases like, "mowing the grass," "killing a president," and "driving a car." Just as the proposition the man mowed the grass can be made true by any number of arrangements of concrete particulars, action-universals like mowing the grass can be instantiated by many different action-particulars. For example, the action-universal mowing the grass can be instantiated by many different particular instances of grass mowing. Now, a person may regard some consideration as a reason for an action-universal, but not some action-particular that is one of its (i.e., the action-universal's) instantiations. I may have a reason to mow the grass (because I want a tidy lawn), but not to mow the grass right now (because it is raining, and my John Deere would turn the lawn into a quagmire). This distinction yields two theses:

1. $A$ is able to intentionally instantiate an action-universal only if $A$ regards some consideration as a reason for its instantiation (i.e., the action-particular).

2. $A$ is able to intentionally instantiate an action-universal only if $A$ regards some consideration as a reason for the action-universal.

The lesson of the IKEA furniture story is that 2 may be true and 1 is false. I surely regard myself as having a reason to pick up a screw, an action-universal (for example, the instructions call for a screw at this point). It might be true that in order to intentionally pick up this screw I must regard some consideration as a reason for the corresponding action-universal. So, my intentionally picking up this screw may satisfy the consequent of 2 , since I do regard some consideration as a reason for the action-universal. Still, contra 1, I need not regard some consideration as a reason for picking up this screw in order to do so intentionally. If we apply these points to the kicking-the-can case, we can say that I like to kick cans down the road (an action-universal). Furthermore, that I regard this or some other fact as a reason for me to kick cans down the road may underwrite the possibility of intentionally instantiating this universal by kicking this can down the road. But, in this case, I can instantiate the action-universal of kicking a can down the road only if I do not regard any consideration as a reason for an action-particular that instantiates this action-universal. Thus, if I intentionally kick

tion between responsibility for event-particulars and event-universals ("Ability and Responsibility"). 
this can down the road, I may satisfy the consequent of 2, but I cannot satisfy the consequent of 1 . Since 1 is false, this is no problem for the case.

We can now consider whether any of the strategies discussed in this paper could reconcile Motivational Constraint with elusive reasons like my reason to kick this can down the road. Sinclair's and Ridge and McKeever's solutions both rely in different ways on the possibility of a reliable advisor who gives the agent at least a motivating reason to act. On Sinclair's view, the agent can be moved to act for their elusive reason so long as the advisor has certain attitudes toward that reason. On Ridge and McKeever's view, the agent can be moved to act for their elusive reason so long as the motivating reason the advisor gives them is Russellian-identical to their elusive reason. Since the fact that I like to kick cans down the road is a reason for me to kick this can only if I do not regard this or any fact as a reason for me to kick this can down the road, it is not clear how the possibility of a reliable advisor, whose advice consists of considerations that $I$ can come to regard as a reason to kick this can down the road, could help reconcile my elusive reasons with Motivational Constraint. LeTrain and I are walking down the road, and LeTrain sees a can in the gutter. He knows that I like to kick cans down the road, albeit only for no reason, and concludes that the fact that I like to kick cans down the road is a reason for me to kick this can down the road. It seems, however, that LeTrain cannot give me a reason to kick this can down the road, since if I come to regard this reason as a reason for me to kick this can down the road, it will cease to be a reason. The same considerations show that the derivative-reason strategy does not help my elusive reason satisfy the Motivational Constraint, even on a revised Motivational Constraint ${ }^{*}$ conception of the latter. That I would be pleased if I kicked this can down the road is a reason in virtue of being explained by the fact that I like to kick cans down the road. But, just like the latter, the former consideration is a reason for me to kick this can down the road only if I do not regard it as such, given that I only like to kick cans down the road if I do it for no reason. But that means that any reason derivative of the fact that I like to kick cans down the road is also elusive.

\section{CONCLUSION}

I have argued that elusive reasons present a serious challenge to the motivational constraint. With respect to one kind of elusive reason, blindspot reasons, I have argued that three strategies for reconciling such reasons with the motivational constraint fail. I then introduced a second kind of elusive reason that, I argued, also cannot be made consistent with the motivational constraint using any of the three strategies previously examined. That the motivational constraint appears 
to be endangered by elusive reasons is a significant result, as it appears to endanger a number of popular views about reasons for action.

Consider what Kieran Setiya calls Internalism about Reasons: the fact that $p$ is a reason for $A$ to $\phi$ only if $A$ is capable of being moved to $\phi$ by the belief that $p .{ }^{44}$ Setiya argues that a wide range of views about normative reasons are best interpreted as arguing for or assuming Internalism about Reasons. ${ }^{45}$ Another version of practical reasons internalism says that $p$ is a reason for $A$ to $\phi$ only if, if $A$ were in circumstances $C, A$ would be moved to $\phi$ by the belief that $p \cdot{ }^{46}$ As noted in section 2 , being moved to act for the reason that $p$ entails having the belief that $p$ and its causing movement to $\phi$. If, in order for $p$ to be a reason for one to act, one must be capable of being moved to $\phi$ by the belief that $p$, or it must be the case that if one were in circumstances $C$, one would be moved to $\phi$ by the belief that $p$, then it must be logically possible for one to be moved to act for the reason that $p$. Thus, both of these views entail Motivational Constraint.

Motivational Constraint is not only relevant to internalist theories of reasons. It is also entailed by views that connect reasons to good practical reasoning. Setiya claims that the fact that $p$ is a reason for $A$ to $\phi$ just in case $A$ has a collection of psychological states, $C$, such that the disposition to be moved to $\phi$ by $C$ and the belief that $p$ is a good disposition of practical thought, and $C$ contains no false beliefs. ${ }^{47}$ Jonathan Way argues that for the fact that $p$ to be a reason for $S$ to $\phi$ is for there to be a good pattern of reasoning from the belief that $p$, perhaps together with other correct attitudes that $S$ has to $\phi$-ing. ${ }^{48}$ Both of these views clearly entail Motivational Constraint. For Way's view to hold, it must be logically possible that one $\phi$ s for the reason that $p$; and this entails that it is logically possible that one is moved to $\phi$ for the reason that $p$. On Setiya's view, $p$ is a reason to $\phi$ only if on the basis of $C$ and $p$ one is able to be moved to $\phi$. This clearly entails that $p$ is a reason to $\phi$ only if it is logically possible that one is moved to $\phi$ for the reason that $p .{ }^{49}$

44 Setiya, "Introduction," 4-5.

45 Including Nagel, The Possibility of Altruism; Williams, "Internal and External Reasons"; Korsgaard, "Skepticism about Practical Reason"; Velleman, "The Possibility of Practical Reason"; Setiya, "Introduction," 2-18.

46 For examples of views that satisfy this schema, see Manne, "Internalism about Reasons"; Joyce, The Myth of Morality; McDowell, "Might There Be External Reasons?”; Korsgaard, "Skepticism about Practical Reason"; Darwall, Impartial Reason.

47 Setiya, Reasons without Rationalism.

48 Way, "Reasons as Premises of Good Reasoning."

49 Way and Whiting have examined the problem of blindspot reasons and offered a response that relies on particular interpretation of the motivational constraint ("Reasons and Guidance”). I hope to respond to that argument in later work. This paper relies on a reading of 
The strategies I have discussed for reconciling elusive reasons with the motivational constraint are not the only ones available, but they are some of the best attempts committed to print thus far. If what I have said is right, then vindicating the motivational constraint - and with it, the theories of practical reasons discussed in this section-must rest on another strategy. ${ }^{50}$

\section{Duke University School of Law brossichi@gmail.com}

\section{REFERENCES}

Arpaly, Nomy. "Moral Worth." Journal of Philosophy 99, no. 5 (May 2002): 223-45. - Unprincipled Virtue. Oxford: Oxford University Press, 2003.

Broome, John. Rationality through Reasoning. Oxford: Oxford University Press, 2013.

Comesaña, Juan, and Matthew McGrath. "Having False Reasons.” In Epistemic Norms: New Essays on Action, Belief and Assertion, edited by Clayton Littlejohn and John Turri, 59-78. Oxford: Oxford University Press, 2014.

Dancy, Jonathan. Practical Reality. Oxford: Oxford University Press, 2000.

Darwall, Steven. Impartial Reason. Ithaca: Cornell University Press, 1983.

Finlay, Steven. “The Reasons that Matter." Australasian Journal of Philosophy 84, no. 1 (2006): 1-20.

Hornsby, Jennifer. "A Disjunctive Conception of Acting for Reasons." In Disjunctivism: Perception, Action, Knowledge, edited by Adrian Haddock and Fiona MacPherson, 244-61. Oxford: Oxford University Press, 2007.

Joyce, Richard. The Myth of Morality. Cambridge: Cambridge University Press, 2001.

Korsgaard, Christine. "Skepticism about Practical Reason." Journal of Philosophy 83, no. 1 (January 1986): 5-25.

Lord, Errol, and Barry Maguire. "An Opinionated Guide to the Weight of Rea-

the motivational constraint that is important because it is entailed by so many common claims about reasons.

50 I would like to thank Robert Audi, Ted Warfield, Jamie Dreier, Sara Bernstein, Meghan Sullivan, Sean McKeever, and two anonymous reviewers for the Journal of Ethics and Social Philosophy for helpful comments and criticisms. Thanks also to participants at the $2018 \mathrm{Ken}-$ tucky Philosophical Association Annual Meeting, the 2018 Great Lakes Philosophy Conference, and the 2018 Wisconsin Philosophical Association Annual Meeting. 
sons." In Weighing Reasons, edited by Errol Lord and Barry Maguire, 3-24. Oxford: Oxford University Press, 2016.

Manne, Kate. "Internalism about Reasons: Sad but True?" Philosophical Studies 167, no. 1 (January 2014): 89-117.

Markovits, Julia. "Acting for the Right Reasons." Philosophical Review 119, no. 2 (April 2010): 201-42.

- Moral Reason. Oxford: Oxford University Press, 2014.

McDowell, John. "Might There Be External Reasons?" In World, Mind and Ethics: Essays on the Ethical Philosophy of Bernard Williams, edited by J.E.J. Altham and Ross Harrison, 68-85. New York: Cambridge University Press, 1995.

McKeever, Sean, and Michael Ridge. "Elusive Reasons." In Oxford Studies in Metaethics, vol. 7, edited by Russ Shafer-Landau, 110-37. Oxford: Oxford University Press, 2012.

- Principled Ethics: Generalism as a Regulative Ideal. Oxford: Oxford University Press, 2006.

Nagel, Thomas. The Possibility of Altruism. Oxford: Clarendon Press, 1970.

Nair, Shyam. "How Do Reasons Accrue?" In Weighing Reasons, edited by Errol Lord and Barry Maguire, 56-73. Oxford: Oxford University Press, 2016.

Paakkunainen, Hille. "Can There Be Government House Reasons for Action?" Journal of Ethics and Social Philosophy 12, no. 1 (September 2017): 56-93.

Parfit, Derek. "Rationality and Reasons." In Exploring Practical Philosophy: From Action to Values, edited by Dan Egonsson, Jonas Joesefsson, Bjorn Petersson, and Toni Rønnow-Rasmussen, 19-39. Farnham, UK: Ashgate Publishing, 2001.

Scanlon, T.M. Being Realistic about Reasons. Oxford: Oxford University Press, 2014.

Schroeder, Mark. Slaves of the Passions. New York: Oxford University Press, 2007. Setiya, Kieran. "Introduction: Internal Reasons." In Internal Reasons, edited by Kieran Setiya and Hille Paakkunainen, 1-34. Cambridge, MA: MIT Press, 2011.

- Reasons without Rationalism. Princeton: Princeton University Press, 2007.

Sinclair, Neil. "On the Connection between Normative Reasons and the Possibility of Acting for Those Reasons." Ethical Theory and Moral Practice 19 (2016): 1211-23.

Sorenson, Roy. Blindspots. New York: Oxford University Press, 1988.

Stroud, Sarah. "Moral Worth and Rationality as Acting for Good Reasons." Philosophical Studies 134, no. 3 (June 2007): 449-56.

Van Inwagen, Peter. "Ability and Responsibility." Philosophical Review 87, no. 2 (April 1978): 201-24. 
Velleman, J. David. "The Possibility of Practical Reason." Ethics 106, no. 206 (July 1996): 694-726.

Way, Jonathan. "Creditworthiness and Matching Principles." In Oxford Studies in Normative Ethics, vol. 7, edited by Mark C. Timmons, 207-28. Oxford: Oxford University Press, 2017.

"Reasons as Premises of Good Reasoning." Pacific Philosophical Quarterly 98, no. 2 (June 2017): 1-20.

Way, Jonathan, and Daniel Whiting. "Reasons and Guidance." Analytic Philosophy 57, no. 3 (September 2016): 214-35.

Williams, Bernard. "Internal and External Reasons." In Moral Luck, 20-39. Cambridge: Cambridge University Press, 1981. 